\title{
Erratum zu: Politiken der Grundbildung im internationalen Vergleich - Von der Politikformulierung zur Implementierung
}

\author{
Carolin Knauber • Alexandra Ioannidou
}

Online publiziert: 2. Dezember 2016

(C) Der/die Autor(en) 2016. Dieser Artikel ist eine Open-Access-Publikation.

\section{Erratum zu: ZfW (2016) 39:131-148 DOI 10.1007/s40955-016-0071-z}

Auf Grund einer technischen Panne wurde in Tab. 1 der Eintrag „England“ in die falsche Spalte gesetzt. Er hätte in der vierten Spalte Institutional autonomy in quasi market systems stehen müssen. Für diesen Fehler bitten wir die Autorinnen sowie die Leser um Entschuldigung. Anbei die korrekte Tabelle.

Tab. 1 Eigene Einordnung der ausgewählten Länder nach Governance-Strukturen bezüglich Grundbildung und Alphabetisierung in die Typologie nach Green et al. (1999)

\begin{tabular}{|c|c|c|c|}
\hline \multicolumn{4}{|c|}{ Models of education regulation and governance (Green et al. 1999) } \\
\hline $\begin{array}{l}\text { Centralized systems } \\
\text { with some elements of } \\
\text { devolution and choice }\end{array}$ & $\begin{array}{l}\text { Regional systems with } \\
\text { some minor devolution } \\
\text { and choice }\end{array}$ & $\begin{array}{l}\text { Local controlling with } \\
\text { national, steering }\end{array}$ & $\begin{array}{l}\text { Institutional autono- } \\
\text { my in quasi market } \\
\text { systems }\end{array}$ \\
\hline Türkei & - & - & England \\
\hline \multicolumn{2}{|c|}{ Österreich } & \multicolumn{2}{|c|}{ Niederlande } \\
\hline
\end{tabular}

Open Access Dieser Artikel wird unter der Creative Commons Namensnennung 4.0 International Lizenz (http://creativecommons.org/licenses/by/4.0/deed.de) veröffentlicht, welche die Nutzung, Vervielfältigung, Bearbeitung, Verbreitung und Wiedergabe in jeglichem Medium und Format erlaubt, sofern Sie den/die ursprünglichen Autor(en) und die Quelle ordnungsgemäß nennen, einen Link zur Creative Commons Lizenz beifügen und angeben, ob Änderungen vorgenommen wurden.

Die Onlineversion des Originalartikels finden Sie unter DOI 10.1007/s40955-016-0071-z.

C. Knauber $(\bowtie) \cdot$ Dr. A. Ioannidou

Deutsches Institut für Erwachsenenbildung - Leibniz-Zentrum für Lebenslanges Lernen, Bonn,

Deutschland

E-Mail: knauber@die-bonn.de

Dr. A. Ioannidou

E-Mail: ioannidou@die-bonn.de 